\title{
ALEXANDRE PINHEIRO TORRES E CAMILO CASTELO BRANCO EM DIÁLOGO INTERTEXTUAL: OBSERVAÇÕES DE LEITURA DO ROMANCE ESPINGARDAS E MÚSICA CLÁSSICA
}

Luiz Maria Veiga ${ }^{1}$

RESUMO: Este ensaio breve procura localizar, no romance Espingardas e música clássica (1987), de Alexandre Pinheiro Torres (1921-1999), o diálogo intertextual com momentos da obra camiliana, procura entender a intenção desse diálogo e fazer uma rápida reflexão sobre seu possível sentido.

ABSTRACT: This brief essay seeks to locate, in the novel Espingardas e música clássica "Rifles and classic music" (1987), by Alexandre Pinheiro Torres (1921-1999), the intertextual dialogue with passages of the Camilo Castelo Branco literary work, seeks to understand the intent of this dialogue and make a quick reflection on its possible meaning.

PALAVRAS-CHAVE: Alexandre Pinheiro Torres; Camilo Castelo Branco; diálogo intertextual KEYWORDS: Alexandre Pinheiro Torres; Camilo Castelo Branco; intertextual dialogue

\section{ESCREVENDO PARA SI MESMO}

Guerra Junqueiro, logo no início do prefácio à segunda edição de $A$ velhice do padre eterno, diz: "Os meus livros imprimo-os para o público, mas escrevo-os para mim.” (JUNQUEIRO, 1967, p. xvii)

Parece que também havia algo semelhante a essa proposta no espírito de Alexandre Pinheiro Torres quando se ocupou, no primeiro semestre de 1962, em escrever o romance Espingardas e música clássica, a respeito do qual pretendemos fazer umas poucas observações. A diferença principal com o declarado pelo poeta de Freixo-de-Espada-à-Cinta é que o romancista não tinha como imprimir seu romance para o público, já que a censura não o permitiria. Portanto deve tê-lo escrito para si mesmo, para divertir-se, retratar e vingar-se um pouco da opressiva realidade vivida naquele princípio de crise final do aparentemente interminável salazarismo. Princípio de crise final - com a retomada da Índia Portuguesa e com o levante armado pela independência nas ditas províncias ultramarinas — ainda muito distante de sua

\footnotetext{
${ }^{1}$ Mestre em Estudos Comparados de Literaturas em Língua Portuguesa pelo Departamento de Letras Clássicas e Vernáculas da Faculdade de Filosofia, Letras e Ciências Humanas da Universidade de São Paulo. Dissertação: Retratos do colono, do colonizador, do cidadão: a representação literária da minoria branca em Nós, os do Makulusu e em outras narrativas angolanas. Ficcionista.
} 
resolução, que só viria a termo doze anos depois, com o ditador já morto, e com o terrível saldo de uma guerra colonial que até os apoiadores do regime, como o general António de Spínola, por fim admitiram: nunca poderia ser vencida.

Um romance que falava na crise da retomada de Goa, Damão e Diu pelo governo da Índia, nos conflitos de classe dentro de Portugal, que tinha como um dos heróis um padre subversivo, irmão de uma espécie de líder operário que, além disso, mantinha ligações e relações imorais com uma filha da classe dominante, e que, para remate de males, retratava com todas as tintas a brutalidade e a estupidez (no sentido de pouca inteligência mesmo) da famigerada PIDE, uma das polícias políticas de mais triste memória num século em que a disputa nessa modalidade reuniu grandes competidores, não tinha mesmo a menor possibilidade de vir a ser publicado. Daí imaginarmos que o autor o tenha escrito para se divertir, como um respiradouro para si mesmo e para uns poucos amigos, da maior confiança, quem sabe? E com a esperança, justificável, que Salazar não havia de durar para sempre.

Pois o romance só veio a público em 1987, um quarto de século depois de escrito, treze anos depois da Revolução dos Cravos. Os leitores tiveram de esperar muito tempo, mas a espera valeu a pena. Foram presenteados com um romance que se lê com vivo prazer, que reúne denúncia social, uma das características mais constantes do chamado neo-realismo português, a uma trama romanesca que tem algo do atrativo do romance policial, e a uma apurada realização de linguagem e forma, com experiências narrativas (o ponto de vista dos cachorros de Frariz, por exemplo) características daquele momento, a década de 1960, terceiro avatar do neo-realismo, se é que podemos dizer assim.

O romance é complexo, múltiplo, de uma riqueza narrativa e estética extraordinária. Não seria possível abordar aqui toda essa multiplicidade. Em virtude disso resolvemos nos concentrar num de seus aspectos principais, algo que poderíamos chamar um dos pilares de sua construção. Ernest Hemingway costumava dizer que escrever romances é fazer arquitetura, não decoração de interiores. Propusemo-nos então a estudar o diálogo intertextual com que Alexandre Pinheiro Torres estruturou seu romance, o diálogo principalmente com Amor de perdição, mas também com outras obras e algo mais do espírito camiliano.

Vejamos o que, a respeito disso, diz Luís de Sousa Rebelo: 
Há, em Espingardas e Música Clássica, um mimetismo voluntário de certas escritas camilianas, que alternam entre a emoção friamente vigiada e o sarcasmo. (...) O sarcasmo assoma nele, por vezes, e o traço grotesco, ocasionalmente caricatural, vale mais do que uma descrição, não escondendo uma violenta revulsão pelo estado de coisas visível à sua volta. A índole e a maneira de sentir, são ainda algo camilianas. (REBELO, 1989, p. 14-15)

Fica então definido nosso propósito: perseguir, no texto de Alexandre Pinheiro Torres, o diálogo com a obra camiliana, procurar entender a intenção desse diálogo e fazer uma rápida reflexão sobre o possível sentido dessa escolha.

\section{COINCIDÊNCIA?}

Imaginemos um leitor do romance que se defronte com o texto sem dele nada saber. Ou melhor, imaginemos dois leitores: um experto e outro inexperto.

O leitor experto na obra camiliana, logo no segundo capítulo de Espingardas e música clássica, há de levantar a sobrancelha, estranhando alguma coisa. Não será no momento em que é mencionado "o juiz Tadeu de Albuquerque" (TORRES, 1989, p. 23), nem talvez no momento em que ouça falar num "Simão" ou quando fique sabendo ser ele, Tadeu, pai de uma "filha Teresa", mas ao saber que há uma criada "Mariana" (TORRES, 1989, p. 24), já não poderá se conter. Vai erguer a sobrancelha e desconfiará muito fortemente que há qualquer coisa de Amor de perdição em todos aqueles nomes. Talvez ele também venha a pensar que Tadeu de Albuquerque, no romance de Camilo, não era juiz. Mas era juiz o pai de Simão. Estariam reunidos numa única figura os dois genitores inimigos entre si e inimigos de seus próprios filhos? A máquina da intertextualidade entrou em funcionamento e não poderá ser detida.

Ao ver o nome do sétimo capítulo ("Teresa e Simão rio acima"), as dúvidas que ainda tivesse acabariam. E se alguma ainda restasse não resistiria quando lesse que Teresa era apaixonada de infância de "Simão dos Botelhos de Friúme, aluno aplicado mas céptico do Seminário de Vila Real". Aquela sequência de palavras (Simão — Botelhos - Vila Real) ecoava puro Amor de perdição.

E ler, logo depois, que o jovem casal 
uma laguna que fosse viveiro de pernaltas. (...) Ao saírem do emaranhado vegetal das ínsuas esbarravam com lavadeiras ou lenhadores a quem muito divertia o espetáculo dos jovens das casas abastadas ou remediadas da vila que passavam as tardes de Estio debaixo das carvalhiças, a gozar não só a sombra mas a alegria dos primeiros amores

talvez venha a lembrar-se de "Maria Moisés" e daquela Josefa da Laje e daquele Antonio de Queirós e Meneses que também andaram um dia à beira daquele mesmo rio:

Ela, para ser feliz até as lágrimas, não precisava destas esperanças. Preferia tê-lo e amá-lo nas matas chilreadas, nos desfiladeiros dos montes, no sinceiral da Ínsua, nas alcovas de ramagens que só eles e os rouxinóis conheciam nas margens de Tâmega.

(BRANCO, 1960, p. 452)

Também ao ler a caracterização do juiz Tadeu de Albuquerque no quarto capítulo como: “desnalgado" (TORRES, 1989, p. 26), o leitor experto há de reconhecer o vocabulário típico camiliano, tão típico que a bibliografia da datação da palavra, no Dicionário Houaiss, é “Camilo Castelo Branco. O comentador. 1890”.

E ainda, no capítulo 19, ao ler o motivo do juiz Tadeu de Albuquerque ter absolvido padre Francisco:

Isto porque Teresa, tinha então dezanove anos e era caloira em Coimbra, lança-lhe o lindo e finíssimo rosto aos pés e jura que se o padre Francisco, pároco de São Frutuoso, for condenado pelo próprio pai dela nunca mais porá os pés lá em casa. Renunciará a todos os bens a que poderá ter direito. Viverá daí em diante da prostituição, de entregar o corpo aos amigos dele. / Tadeu de Albuquerque lembra-se logo dos Soares, de Vila Meã, do Freitas de Fermil, do Torrado de Celorico, do Henrique Sena de São Miguel de Porreiras, do Pereira Correia de Rifontoura, do Lopes Dinis de Agualonga, uma longa lista de amigos que já topara a examinar-lhe, de olho aceso, a filha única, os porcos. (TORRES, 1989, p. 26)

Ao ler essa ameaça de Teresa, como não há nosso camiliano leitor de se lembrar de outra filha, que não ficou só na ameaça, depois do pai ter-lhe dado fim ao amado com uma clavina:

Maria seguiu as pisadas do pae para o Porto. Chegou ao Porto, e alugou uma casa térrea, fronteira ao quartel militar de S. Bento, onde o pae podia vel-a. Depois mandou dizer ao pae que estava alli. O pae foi ás grades eminentes á casa térrea, e viu a filha sentada no degrau 
da porta. Maria fincou os cotovellos nos joelhos, e a barba nas palmas das duas mãos, e contemplou seu pae. Em seguida passava um grupo de soldados, e pararam defronte d'ella. E o pae via tudo com a cabeça entre os varões de ferro. E Maria ergueu-se do limiar da sua porta, e entrou com o soldado n'uma taberna visinha. / E depois sahiu da taverna, e entrou com o soldado em sua casa. / E o pae viu tudo com a cabeça entre os varões de ferro. / E depois... / Na lista da prostituição foi inscripto o nome de $\mathrm{M}^{* * *} \mathrm{E}^{* * *} \mathrm{~S}^{* * *}$, que disse ser filha do morgado do $\mathrm{R}^{* * *}$. (BRANCO, 1927, p. 54-55)

O leitor experto há de com certeza pensar que aquilo que foi tragédia em Camilo Castelo Branco, reaparece como farsa no romance de Alexandre Pinheiro Torres. Eis uma das passagens que parecem reforçar aquela idéia do romance ter sido escrito, entre outras coisas, por divertimento. Ainda que por vezes um amargo divertimento.

\section{E O OUTRO LEITOR?}

O outro leitor, o leitor inexperto, não foi deixado entregue ao seu próprio desconhecimento pelo romancista de Espingardas e música clássica. Fica claro que era propósito dele não permitir a nenhum leitor a possibilidade de não perceber o diálogo intertextual com a obra do Visconde de Correia Botelho. E já que estamos nos referindo a títulos nobiliárquicos, é tempo que falemos de uma nova personagem, que não é homônima de nenhuma outra, de outro romance, mas vai ser a guia do leitor inexperto:

D. Briolanja Valadares de Cerveira e Távora de Meneses que vivia, viúva e sem filhos, na sua grande propriedade de Cabeça Santa, cerca de Penafiel, cuja casa se acreditava ser o antigo paço de Abragães e Boelhe, rico-homem que descendia de um bastardo de D. João III, mas com linhagem que recuava até ao quarto conde de Barcelos. (TORRES, 1989, p. 45)

O leitor experto já reconheceu esse tom de linhagens e prosápias, visto em muitos dos chamados romances históricos do recluso de São Miguel de Seide. (Caso de O senhor do Paço de Ninães, por exemplo, ou, num registro satírico, o Calisto Elói de Silos e Benevides de Barbuda, morgado de Agra de Freimas, herói de A queda de um anjo.)

O leitor inexperto é, em seguida, informado: "No solar de Cabeça Santa viveu D. Briolanja muitos anos entretida a aumentar o patrimônio, mas mais enlevada a ler os 
romances de Camilo e a recordar os seus tempos de casada em Braga." (TORRES, 1989, p. 45) E mais adiante: "Ela trouxe as melhores mobílias para Frariz e, sobretudo, a sua valiosíssima camiliana e preparou-se para educar a sobrinha-neta." (TORRES, 1989, p. 46) Esta sobrinha neta chama-se Fernanda, é prima de Teresa e uma espécie de protetora dos amores secretos desta com Simão.

Também neste momento é introduzido no romance o pai de Simão, "o caseiro Serafim Pereira Botelho, que viera das funduras de Friúme" (TORRES, 1989, p. 47) e será o outro leitor explícito de Camilo Castelo Branco, a figurar no romance, embora, como veremos, tenha se limitado a ler um único livro desse autor.

E aqui, embora seja longa, será indispensável fazer integralmente a citação das especulações feitas por D. Briolanja e o diálogo com seu caseiro, porque essa é uma das duas chaves (poderíamos dizer que é a chave de abertura do problema) para que o leitor inexperto, e o leitor experto também, percebam que há mais personagens homônimos de outros e as relações que Alexandre Pinheiro Torres articulou entre os textos que pôs em confronto:

Havia uma coisa, porém, que fazia espécie a D. Briolanja. Era o nome do terceiro em idade, Simão Botelho. Não era idêntico ao do herói do Amor de Perdição? Ora, ela sabia que em Frariz havia um juiz Tadeu de Albuquerque que tinha uma filha única chamada Teresa. A fidalga de Cabeça Santa sorriu-se com a coincidência e diga-se que não era para menos porque, entre a parentela, tinha dois sobrinhos gémeos por apelido Coutinho, ainda do ramo dos Alvezes, cujos nomes eram D. Baltasar e D. Lucanor. Uma, duas coincidências, vá, mas quando ela descobriu que eram pelo menos três, mandou vir do Porto livros sobre Cálculo das Probabilidades, dos quais nada entendeu. // Por inculcas de amigos, contactou com o catedrático da cadeira na Faculdade de Ciências do Porto, um tal Hermenegildo Queirós, homem de grande reputação, pai de onze filhos e cristão devotadíssimo. Pôs-lhe por carta o problema: qual a probabilidade de personagens com os mesmos nomes do Amor de Perdição surgirem, de novo, numa área qualquer do Norte de Portugal? O pobre do professor Hermenegildo teve de ler, de novo, o romance de Camilo Castelo Branco, contou o número de personagens que entendeu eram as que importavam, e respondeu a D. Briolanja que a probabilidade era uma em quatro mil trezentos e vinte e seis anos. // A aristocrata riu-se da ciência de Hermenegildo. Pois então ele não sabia que os nomes de Simão e Teresa se tinham tornado imensamente populares depois do sucesso do romance? Botelhos havia muitos. Pai apelidado Botelho, que tivesse chorado ao ler o drama camiliano, caso houvesse filho macho dar-lhe-ia logo o nome de Simão. Mandou chamar o caseiro e perguntou-lhe: // "Por que escolheu vossemecê o nome de Simão para seu filho?" // O Serafim, espantado com a pergunta, respondeu: // "Minha senhora, 
nós somos de Friúme. Por lá andou e até casou o escritor Camilo Castelo Branco. Só a sul de Arco de Baúlhe, que ainda é Ribatâmega, como V. Ex. a saberá, há oito famílias Botelho. Uma em Padredo, duas aparentadas em Vila Nune, uma em Lourido, outra em Britelo, outra em Canedo, outra em Vila Nova de Quires e ainda outra em Soalhães. Isto que conste. $O$ que dá oito Simões Botelhos!" // "Oito? Vem algum de famílias fidalgas?" // "Saiba V. Ex. ${ }^{a}$ que não. Os Botelhos de Camilo eram Mesquita e Meneses. Todos os outros Botelhos não são nem uma coisa nem outra. $O$ botelho, sabe bem V. Ex. a , é uma medida de grãos de farinha que por todas estas ribas cheias de açudes muito se usa. Palavra de farinheiro, é uma forma de ladrar à Lua, tentar meter o braço até ao cotovelo." // "Vossemecê sabe muito de Camilo." // "Minha senhora, todos nós, os de poucas letras, só lemos até hoje o catecismo e o Amor de Perdição." // "E vossemecê gosta do livro?" // "Só leio quando preciso de chorar." // "Por isso vossemecê deu a um filho o nome de Simão?" // "É a pura da verdade. Se me chamasse Cruz e tivesse uma filha havia de se chamar Mariana. Permita-me que lhe diga que só se molha a vela quando há vento." // "Vossemecê sabia que em Frariz há um Tadeu de Albuquerque que tem uma filha Teresa?" // "Nunca estive em Frariz. Mas se há um Albuquerque que se chama Tadeu que dianho de nome, desculpe-me V. Ex.., havia ele de dar à filha? Basta puxar um bocadinho pelo cacanho." // "Então para vossemecê não seria surpresa se uma família fidalga de apelido Coutinho tivesse por filho primogénito o nome de Baltasar." // "Não me surpreendo, $\mathrm{Sr}^{\mathrm{a}}{ }^{\mathrm{a}} \mathrm{D}$. Briolanja, embora Baltasar tenha ficado para sempre como palavra para cabeça de abrotes, fanfas e matrefão. O que vale é que Simão Botelho, no romance de Camilo, manda-lhe um tiro à freguesia dos ossos, mas se algum Coutinho quiser chamar ao filho Baltasar e arriscar-se a que o rebento leve outro balázio, isso é lá com ele." // "Então vossemecê acredita que o seu filho Simão está destinado a apaixonar-se por uma Teresa e a tornar-se assassino por causa dela?" // O caseiro Serafim pôs-se a rir com a devida reverência. // "Saiba V. Ex. a que não acredito. Poderá encontrar uma Teresa, mas matar por amor não lhe vejo jeitos. Se a Exm. ${ }^{a} \mathrm{Sr}^{\mathrm{a}}{ }^{\mathrm{D}} \mathrm{D}$. Briolanja quiser usar da caridade que usou para os outros meus filhos, era deixá-lo crescer e mandá-lo para o seminário. Meu filho não há-de justiçar nenhum Baltasar Coutinho." // Ela sorriu e disse a Serafim Botelho que podia ir à vida dele. (TORRES, 1989, p. 47-49)

\section{UM DEPOIMENTO}

Em abono da verossimilhança das declarações literárias do caseiro de D.

Briolanja, e também a título de curiosidade, cabe aqui a transcrição de um depoimento feito por Antonio Houaiss:

A riqueza da linguagem camiliana tem, porém, uma tal vitalidade, no geral, e é tão comunicante, que Camilo pode ser lido ou ouvido por leitores ou ouvintes portugueses semiliteratos com quase completa intelecção. Que se me permita um depoimento autobiográfico, válido 
para o caso: o primeiro 'emprego' remunerado do signatário destas linhas terá seguramente sido o de ler, para suados e cansados assalariados portugueses do então fazia pouco inaugurado Copacabana Palace Hotel, que viviam em 'república' no Leme, no Rio de Janeiro, durante um par de horas a cada dia, à noitinha, romances e romances de Camilo Castelo Branco. Seus ouvintes, na maioria - seriam oito ou nove - eram analfabetos, ou pouco mais (ou menos); mas sua atenção, roubada ao sono e ao mais que merecido repouso, era infatigável; lembro-me de que se tentou também algo de Eça, de João Grave, de Antero de Figueiredo - que sei eu; mas só Camilo, de forma insuperável, fazia-nos comungar com as situações, os heróis, os algozes, tomando partido, esperançando-se, desesperando-se, suspirando, sorrindo (pouco), chorando (não raro). Grande rapsodo de sua gente, sua gente compreendia-o e compreendê-lo-á por muito tempo ou sempre. (HOUAISS, 1979, p. 196-197)

\section{ORGANICIDADE DO DIÁLOGO INTERTEXTUAL}

Mas que não se pense que essa longa conversa sobre a obra camiliana e sua recepção, que tiveram D. Briolanja e o caseiro Serafim, é um parêntese, um comentário, separado da estrutura do livro. De maneira nenhuma. Tudo está misturado, a evocação do romance do século XIX com a ação do romance do século XX. Enquanto Simão, Teresa, Mariana, Tadeu de Albuquerque, Baltasar Coutinho vivem suas vidas ficcionais na maior parte do tempo inconscientes de sua condição de homônimos dos personagens de outro romance, e os dois leitores camilianos colocam em evidência essa circunstância, também vemos outros resultados da leitura do romance, na prisão que os agentes da PIDE fazem, não de um, o verdadeiro, mas de três outros Simões Botelhos. Assim fala o agente a seu superior: "Com tanta sorte que com o nome de Botelho descobriram três famílias e logo nas três havia outros tantos Simões. Resolveram prendê-los a todos, à cautela. Aqui se desenrascaria a meada."

E era à base de tortura, como vemos depois, que pretendiam desenrascar a tal meada: "No estado em que o Pintadinho lhes deve ter deixado a cara deve ser difícil a identificação (...)" (TORRES, 1989, p. 94, vale para a citação anterior).

\section{UMA POSSÍVEL RESPOSTA: ATRITO ENTRE REALIDADE E FICÇÃO}

Ainda há mais exemplos e mais diálogo, entre a obra de Alexandre Pinheiro Torres e a de Camilo Castelo Branco, mas nem seria possível nem aconselhável colocar todos aqui. Mas será indispensável citar o diálogo final entre D. Briolanja e o caseiro 
Serafim, em que é feito uma espécie de balanço, de paralelo entre o que acontecia no romance de Camilo e o destino dos seus duplos no romance que estamos examinando:

D. Briolanja deteve-o: // "Mudemos agora de assunto. Sabe vossemecê que esta nossa mania do Camilo me põe doida?" // "Não sei porquê. Afinal, mesmo com os nomes idênticos aos de Amor de Perdição, nada se repetiu. A Mariana não se atirou afogada agarrada a nenhum cadáver, temos Teresa casada ou amigada, qualquer dia, com o Simão, tanto faz. Tadeu de Albuquerque deve ter tido que amochar, claro que se vê que amochou. Sr. ${ }^{a}$ D. Briolanja, os tempos são outros! Qual era a proprietária que na época de Camilo oferecia dez hectares ao caseiro nem que ele tivesse trabalhado cem anos? E o que acontecerá daqui a outro século, se ainda houver mundo, que, para nós, já não o haverá." // "Nada se repete, Serafim, é verdade, mas o que você não sabia é que Camilo nunca nos contou uma história que realmente tivesse acontecido." // "Essa agora!", protestou o caseiro. "O Amor de Perdição é uma bíblia. Então eu não sei? Não sou de Friúme onde ele foi casar aos dezesseis anos com a Joaquina Pereira, lavradeira de rabo sujo, com a licença de V. Ex. ${ }^{a}$, que tem parentela que é ainda da minha família?" // "Olhe, Serafim, esgotados os Camilos comecei a ler os eruditos que têm andado a espiolhar a vida dele. Você sempre pensou, por exemplo, que o pai de Simão Botelho era fidalgo. Pois não era, não senhor. Era mais plebeu que vossemecê." // "Então como ficou fidalgo?" // "Ficou fidalgo na cabeça de Camilo." // "Quer V. Ex. dizer que nos enganou toda a vida?" // "Toda a vida, Serafim. E mais: Baltasar Coutinho nunca existiu." // "Nunca existiu?" // "Nunca. Outra invenção de Camilo." // "Mas o sobrinho de V. Ex. a, com o mesmo nome, esse existe, não podemos ter dúvidas." // "Existirá?" // "Oh $\mathrm{Sr}^{\mathrm{a}}{ }^{\mathrm{D}} \mathrm{D}$. Briolanja, a senhora brinca?" // "Não brinco. Mariana também nunca existiu a não ser na cabeça do romancista." // "Mas então o Amor de Perdição não são as verdadeiras "memórias de uma família'?" // "Você que lhe quer? Verdadeiras não são." // "Quer dizer V. Ex. a que por essa Ribatâmega acima, que digo?, por esse Portugal todo, tem havido montes de gente a chorar por causa de Simão e Teresa e que isso também não é verdadeiro?" // "Não foi verdadeiro na vida. Pensa-se, uma das várias hipóteses, que Simão foi condenado por dar um tiro no pai e não em Baltasar, que não existia. Aliás, Simão foi degredado por essa razão, mas chegou à Índia, nunca morreu na barra do Douro, isto dizem os sábios das universidades." // "Então a gente anda a chorar por uma coisa que não aconteceu?" // D. Briolanja andava a brincar com o lorgnon: // "Mas aconteceu no romance. A si que lhe importa que não tenha acontecido na vida?" // "Ora essa! V. Ex. ${ }^{\text {a }}$ brinca com certeza, nunca mais tocarei em tal livro, o meu único livro." // "Engano, vossemecê vai tornar a pegar nele e vai voltar a chorar outra vez. A princípio a minha reacção foi como a sua. Odiar Camilo, o mentiroso. Amuei. Mas quando soube que a Teresa de Albuquerque de Frariz ia ter a França com o Simão Botelho de Friúme, não sei que senti na alma, toda esta história desta vila de Ribatâmega me pareceu uma troça, um caso sentimental de uma banalidade sem fim. Este romance de 
Frariz é que me pareceu falso. Digo-lhe mais, Serafim, não há nada de mais falso no mundo. Os eruditos não sabem nada, percebe? O Amor de Perdição é que é uma memória autêntica. Não há uma palavra nele que seja mentira. Podemos continuar a chorar pela sorte de Teresa, Simão e Mariana.” (TORRES, 1989, p. 246-247)

\section{CONSIDERAÇÕES FINAIS}

Quando D. Briolanja, em meio a esse balanço final, depois de informar que aqueles personagens de Camilo são apenas personagens, nunca existiram de verdade, pelo menos não na forma da narrativa que ele criou, ao ouvir Serafim, em oposição a isso, afirmar a existência do sobrinho dela, Baltasar Coutinho, pergunta: "Existirá?", parece estar lançando um desafio ao leitor. Parece de alguma forma querer dizer que aquilo que está sendo dito sobre a ficção de Camilo é também uma advertência sobre a ficção de Alexandre Pinheiro Torres.

Há, na estrutura do romance, uma oposição entre realidade presente e aparente, o que está acontecendo em Frariz do Tâmega nos últimos dias de 1961 e primeiros de 1962, e uma espécie de discussão metalinguística a respeito de uma antiga obra de ficção, que está fazendo exatos cem anos de vinda a público. Uma oposição (aparente, pelo menos) entre realidade material e literatura, uma tentativa de representação da realidade material.

Mas Alexandre Pinheiro Torres, ao por diante de nossos olhos, personagens que lêem livros e falam nos personagens dos livros que lêem, de certa maneira nos remete à posição em que também estamos: como D. Briolanja e Serafim, nós também estamos na realidade material (e estamos de fato, a menos que sejamos personagens de um romance que está sendo escrito por Deus) em contato com personagens imaginários, que povoam um universo ficcional. D. Briolanja, quando duvida da existência do sobrinho — por que deveria fazê-lo, na lógica da realidade em que existe? — está nos lembrando, aparentemente, que não só aquele Baltasar não existe, como ela mesma, e todos os outros personagens do romance não existem, ou melhor, só existem dentro daquele universo criado. E nos importa alguma coisa, a nós leitores, que com tanto gosto desfrutamos desta obra de arte, que ela só tenha acontecido no romance, não tenha acontecido na vida? Não, porque expertos ou inexpertos, todos nós, leitores de romances, já adquirimos o gosto pela ficção, sem nada mais pedir a ela além de que seja 
boa, sempre da melhor qualidade estética e humana, valores que não temos motivo nenhum para relativizar.

A declaração que D. Briolanja também faz, sobre ser Amor de perdição uma memória autêntica, nele não haver uma palavra que seja mentira, parece uma afirmação orgulhosa e consciente que pode ser estendida a toda ficção, essa forma especial de mentira que, para ser arte autêntica, deve se sustentar, paradoxalmente, da mais rigorosa e íntima verdade humana. A complexa realidade do mundo material nunca será completamente verdadeira para nossa consciência, porque é inapreensível em sua totalidade. Já a realidade ficcional é absoluta. Nada mais aconteceu além daquilo que está escrito ali. E é tudo verdade. Ainda que possa ter muitos sentidos, é tudo sempre verdade. Não existe nenhuma outra possibilidade de não ter acontecido (no livro) algo mais além daquilo que está escrito ali.

\section{REFERÊNCIAS BIBLIOGRÁFICAS}

BRANCO, Camilo Castelo. Memorias do carcere, v. II. Lisboa: Parceria Antonio Maria Pereira, 1927.

. Obra seleta, v. II. Org. Jacinto do Prado Coelho. Rio de Janeiro, José Aguilar, 1960.

HOUAISS, Antonio. "Sobre Camilo Castelo Branco" in Estudos vários sobre palavras, livros, autores. Rio de Janeiro: Paz e Terra, 1979, p. 189-199.

JUNQUEIRO, Guerra. A velhice do Padre Eterno. Porto: Lello \& Irmão, 1967.

REBELO, Luís de Sousa. "Prefácio à edição portuguesa" in Espingardas e música clássica. São Paulo: Estação Liberdade, 1989, p. 9-16.

TORRES, Alexandre Pinheiro. Espingardas e música clássica. São Paulo: Estação Liberdade, 1989. 